\title{
Uncovering Myself to Understand You
}

\section{Develándome a mí mismo para entenderte}

\begin{abstract}
Sayra Milena Lozano Carvajal ${ }^{1}$ Santiago Velásquez Tangarife ${ }^{2}$
\end{abstract}

Citation/ Para citar este Artículo: Lozano, S. E Velásquez, S. (2017). Uncovering Myself to Understand You. Colomb. Appl. Linguist. J., 19(1), pp. 129-139. Received: 21-Dec-2015 / Accepted: 26-Sept-2016

DOI: http://dx.doi.org/10.14483/calj.v19n1.9892

\begin{abstract}
Classroom incidents in which teachers have to exhibit their expertise at managing a class is commonplace in teachers' daily routines, though sometimes some of those classroom incidents turn into critical moments. However, ordinary disruptive classroom situations are not as catastrophic as when teachers themselves provoke them. In addition, when some teachers have to face any sort of classroom disruption, most of them are unable to come up with any immediate and effective solutions. In this paper, we describe how we combined both the critical incident technique and the cooperative development theory so as to reflect upon a critical moment of each of us to be able to improve our viewpoints regarding the potential solutions that can emerge to cope with those critical moments in our own classrooms. The findings show that we strengthened our professional ties, we invigorated our teaching skills, and developed from our own insights into new perspectives in relation to how to better tackle classroom management difficulties. Finally, we share how profound the changes were which, additionally, were not only in the pedagogical sense.
\end{abstract}

Keywords: classroom management, collaborative work, professional development, reflective teachers

\section{Resumen}

Los incidentes de clase en los que los profesores deben poner a prueba su experticia para manejar un salón de clase son el pan diario de los docentes aunque hay veces en las que esos incidentes se vuelven momentos críticos. Sin embargo, ninguna situación difícil de un aula es más catastrófica que aquella provocada por el docente mismo. Como si esto fuera poco, cuando algunos profesores tienen que lidiar con una situación de clase, la mayoría de ellos no logran resolverlas de manera inmediata y efectiva. En este artículo, describimos como los autores combinamos la teoría del desarrollo cooperativo con la técnica llamada incidente crítico con el fin de reflexionar acerca de un momento crítico de cada uno y así poder mejorar nuestras perspectivas en relación con las potenciales soluciones que emerjan para resolver ese momento crítico de nuestra experiencia individual. Según los hallazgos, se evidencia que los participantes en este proyecto fortalecimos nuestros lazos profesionales, revitalizamos nuestras habilidades de enseñanza y desarrollamos, partiendo de nuestras reflexiones, mejores maneras de resolver las dificultades de manejo de clase. Finalmente, en las conclusiones compartimos cuan profundos fueron los cambios que, dicho sea de paso, no solo fueron a nivel pedagógico.

Palabras clave: desarrollo profesional, profesores reflexivos, trabajo colaborativo, manejo de clase.

1 Universidad del Tolima. Tolima, Colombia. yosayrax@gmail.com

2 Universidad del Tolima. Tolima, Colombia. svelasquezt@ut.edu.co 


\section{Introduction}

Teaching is a daily activity embedded in human interactions. What makes teaching different from other professions which are also based on human interactions is the fact that there is only one teacher in the classroom exchanging knowledge and experiences with many students at the same time. Based upon experience we may say that some disruptions emerge in a classroom from those human interactions in which the student-to-student incident is the most prevalent type and in which the teacher, as cause of disruption, may be also the case. Regardless of the origin of the disruption, if any in-service teacher does not have the time or the inclination to reflect on those negative situations, they may end up treating their classroom disruptions permissively; unfortunately, we all know that the lack of reflection and action may turn any negative but manageable classroom situation into a disaster. In a word, sometimes the way some teachers tackle their classroom difficulties may alleviate temporarily a class situation but, in fact, those decisions are not solving it at all, they are simply making the problem grow secretly.

When we, the authors, had to cope with a similar problematic situation in our respective educational contexts, we almost fruitlessly struggled to find a practical and effective solution, until we learnt about critical incident $(\mathrm{Cl})$ and cooperative development theory (CDT) which made us feel relieved. First of all, we learned about $\mathrm{CI}$ and wrote our own $\mathrm{Cls}$ and used them to analyse the class situation before moving to the implementation of the CDT. This theory helped us clarify what particular aspects from our personal class situation we had to focus on the most and what other elements embedded in the class situation we were probably overlooking so we could prevent any similar situation to arise again.

For this study, we created a hybrid technique implementing the critical incident in combination with the cooperative development theory. The purpose was to analyze one teaching incident per teacher and find out what different solutions this mixed technique would offer us to deal with class disruptions more successfully. For $\mathrm{CI}$ theoreticians, class incidents or class disruptions happen normally, but what makes them critical are the interpretations of the event, the significance for the class and the teacher's ability to turn them into a positive learning experience. Similarly, Tripp (1993) maintained that "[critical incidents] are an excellent way to develop an increasing understanding of and control over professional judgement, and thereby over practice" (p. 24). CDT is, instead, more complex, more demanding and more significantly rewarding in the sense that it means to work together with a peer "to collaborate on furthering ideas and plans of one of the pair" (Edge, 1992, p. 62).

In regards to time, the writing of a $\mathrm{Cl}$ or the implementation of the CDT might not seem as practical and quick as some teachers could expect them to be, but both theories offer great opportunities to grow personally and professionally. A case in point for $\mathrm{Cl}$ is that of Farrell (2008) who "outlined and discussed how eighteen trainee teachers reflected on $\mathrm{Cl}$ that occurred while they were teaching" (p. 3). Farrell concluded that "[after] reflecting on the various Cls that occurred in their team teaching sessions. . . the participants were better placed to face the realities of teaching" ( $p$. 10). Concerning CDT, there are two studies we can quote. In one of them, Mann (as cited in Johnson $\mathcal{E}$ Golombek, 2002) presented both a clear example of how to implement the CDT and the benefits it brought to the teacher's practice. In another study, Boshell (as cited in Johnson \& Golombek, 2002) explained how he realized that he himself was discouraging students from participating in class and how his colleagues of the study group helped him become aware that he lacked faith in students. Boshell concluded that without his colleagues help he "would never have been able to come to realize exactly why and how [he] was thwarting [the students'] participation in class" (as cited in Johnson \& Golombek, 2002, p. 194).

Moving back to our experience with the $\mathrm{Cl}$ and the CDT, the present study was divided into two different phases. In the first phase, teacher $\mathrm{A}$ (TA), a female teacher, played the role of speaker and told teacher B (TB), a male teacher who was the understander, about the $\mathrm{Cl}$ she wrote and the conclusions she drew from its analysis. Only then we initiated the implementation of the CDT. To do 
this, we pre-scheduled the amount of sessions per week for us to meet. We decided on the type of instruments to use for data collection (namely audio and video recordings of the sessions and note-taking of the ideas expressed by the speaker), the analysis of the audio and videos to code the data and group it into categories, the attendance and recording of the speaker's classes, and the evaluation of the teacher's development in the light of class observation sheets. As part of the implementation, we also discussed how we would record the information, how we would analyze it, as well as what for, the structure that the different sessions would follow, how long they would take, and how much each speaker would like to go into her/his CI. Once this first round was complete, we moved to the second one. The only difference between both rounds lay on the role each participant played. That is, TA who was initially the speaker, played the role of understander in the second round. Consequently, TB would play the role of speaker and have the same opportunity to tell his colleague about the conclusions reached through the writing of his CI before initiating with the implementation of CDT, which would follow the same steps listed above. All of these considerations were taken under the premises and principles of the CI and CDT as proposed by Farrell (2008) and Edge (1992), respectively.

\section{Literature Review}

As has been indicated previously, this study is carried out through the mixture of two theories: the critical incident, and the cooperative development. In this section, we will share the elements of both concepts that made possible the development of the work. The CDT emerged with Edge's (1992) intention of acquiring professional development through the aid of colleagues, but starting from the idea that teachers are "usually motivated by a desire for self-improvement" (p. 62). This statement shows that despite having partners who are ready to work for a mutual goal, a personal decision of growing professionally has to come from teachers. Once all teachers are ready to listen for acting and reflecting, the CDT becomes a powerful tool to guarantee a sense of comprehension, generosity, solidarity, and respect among the participants.
The idea of professional development in the CDT originates from the evolution it has had during the last few years. Teachers have always wanted to be updated in regard to the latest innovative and successful pedagogical strategies to improve teaching and learning practices. As a consequence, several researchers have proposed professional development as a path for advancing towards a deeper understanding of teachers' roles. One example of this is teacher development by Richards and Farrell (2005) who have also shared their experiences about professional development. The commonality of this with CDT lies in the fact that the latter "serves a longer-term goal and seeks to facilitate growth of teachers' understanding of teaching and of themselves as teachers" (p. 4). Both theories assert that teachers want to comprehend their teaching acts by:

- Understanding how teachers' roles change according to the kind of learners they are teaching.

- Reviewing the teachers' own theories and principles of language teaching.

- Developing an understanding of different teaching styles.

- Determining learners' perceptions of classroom activities.

(Richards \& Farrell, 2005, p. 4)

It is in this way that professional development becomes a powerful tool for CDT to stop treating teaching as a systematic act and to give the treatment that education deserves through the collaborative examination of beliefs, values, and principles and the discovery of new ways of thinking about teaching.

After having described professional development, understood as one of the main characteristics of CDT, let us mention how this is reached throughout the work done with others. This is based on a non-judgmental discourse between colleagues where participants contribute to the construction of a cooperative work to improve teachers' teaching knowledge by focusing primarily on the being. To reach such a meaningful purpose, Edge (1992, p. 63) proposed the use of three values: respect, honesty, and empathy which must 
be exhibited by the understander. Edge conceives respect as the ability to accept without judging what the speaker wants to tell. Regarding empathy, he considers it as an understander's ability to see the classrooms, the students, the contexts, and the teacher together through the frame of reference of the speaker and retell it using his/her words so the speaker can see and hear his/her own positions in a supportive environment. Finally, Edge (1992) defines honesty as the understander's ability to respect and empathize with the speaker's ideas and views regardless of his/her agreement or disagreement.

Now, in order to activate the professional desires and goals of the speaker in our research project, we had to implement a hybrid mixture of CDT and CI. This last, according to Farrell (as cited in Richards E Farrell, 2005) "is an unplanned and unanticipated event that occurs during a lesson and that serves to trigger insights about some aspect of teaching and learning" (p. 113). Farrell added that it can be called a critical incident because "it prompt[s] the teacher to stop and reflect on the meaning of the event and perhaps to consider its longer-term implications" (pp. 113-114). This idea fits perfectly with the intention of making teachers understand the principles that surround their practice, and makes their way of teaching more practical and efficient. This CI is developed through a format proposed by Tripp (as cited in Richards \& Farrell, 2005, p. 118). The first stage is 'the what' in which the event is initially described without any justification; it means that the speaker exposes the incident without subtracting anything and without involving any type of feeling. Consecutively, "the why" in which the events and the emotions that came out are explained and the teachers try to find the reasons that made the incident appear. Finally, there is "the how" which is a section from the $\mathrm{CI}$ where the speaker reflects upon the situation, becomes better informed about any of the elements involved, and decides on what actions to take. These stages allow the teacher to consider thoughtfully the events embedded into the incident and address them to specific solutions.

In order to trigger the features of CDT, the participants need to acknowledge some specific criteria during the process of playing two roles: the speaker and the understander. The speaker is primarily the one that activates the CDT through his/her decision to start a path of knowledge about his/her feelings as a person and beliefs as professional by using the $\mathrm{Cl}$ as the starting point. Thus, the speaker has to follow some specific requirements to guarantee a perfect development of the CDT. It is in that way that the speaker has to remove any defensive style when sharing his/her critical incident or when hearing the reflections of the understander, based on the idea that he/she as the speaker, is not being evaluated. Then the speaker explains clearly his/her issues focusing on specific aspects of the critical incident, avoiding digressions, and reconciling through clarifications or explanations his/her speech when the understander requires it. The speaker must be also open-minded to face any emotional encounter such as frustration, denial, or disappointment. Additionally, he/she must be ready to trust others, decide what changes to make and how to move away from the critical moment that ignited the CI. It is relevant to highlight that the speaker decides how far he/she wants to go with his/her $\mathrm{Cl}$ account. On the other hand, the understander will have to accomplish the role of listening with all his/her humanity. In other words, the understander must abandon his/her personal judgments to empathize with the interlocutor by observing the world through his/her eyes. Similarly, the understander must provide support and opportunity for reflection, clarification, and action. Instead of thinking of the solutions, the understander has to think of the ways in which he/she can help the speaker to find his/her own way. The understander neither agrees nor disagrees with what the speaker says but fully respects his/her choice of topic and the ways in which he or she chooses to explore it. The understander also facilitates progress along the lines of the speaker's professional development goals. Hence, it is possible to evidence that these roles are created, not only to develop abilities related to the educational field itself, but also, to maximize the potentialities of the being by starting with the recognition of the other as someone who needs help and support.

Having briefly explained the structure that supports CDT, it is indispensable to discuss how all the named elements can be mixed to contribute to teachers' development. Once the speaker has shared 
his/her critical incident with the understanders (it can be more than one), some steps are carried out in order to allow the participation of the teachers reflectively, honestly, empathetically, and respectfully. These steps also guarantee that the issues presented in the critical incident could be analyzed and be ready for action.

In that order of ideas, the participants start with the phase of attending, which is simple but difficult to implement, because it compels the understander to engage in profound listening, in which any attempt of judgment might eventually appear, provided that judging is part of human nature. The speaker has to feel that he is being listened to, and that his/ her words have meanings for the understander. Subsequently, good listening from the understander naturally leads to the reflecting phase where the speaker reflects on his/her own comments through the questions that the understander found relevant to ask according to the speaker's CI. Then, good reflection takes both participants to the focusing phase in which the understander helps the speaker to have more focus about some aspects of his/ her speaking in order to better comprehend the situation and enhance a deeper reflection. Later, if connections are required during the procedure, the understander's abilities are the ones that will find those connections before moving to the next phase called thematising. Here is where the speaker confirms the discoveries that the understander has made about the speaker's incidents. In the next phase, the challenging phase, the understander is in charge of finding contradictions in the speaker's statements, if it is like that, the understander makes him/her aware of them with the aim of making him/ her notice that his/her speech lacks of coherence. For the understander, it is important that everything is clear, in that way he/she can continue working under the speaker's perspective, but again, it is the speaker who chooses whether to consider this possibility or not, because it is he/she who needs to feel satisfied with the findings along this study. Next, in the disclosing phase, if clarifications to comprehend what the speaker tries to say are required, the understander gives an experience of his/her own, and the speaker uses it as a point of reference to compare it with his/her own experience and clarify what he/she is trying to say to the understander. Then, taking into account that CDT is an action-oriented activity that advocates teachers' self-motivated positive change, Edge (1992) proposes the goal setting phase to promote that teachers set a goal based on the advances he/ she has achieved throughout each of the phases. It is important to have in mind that the goal has to be attainable; "the smaller the goal, the better the chance of acting towards it and being able to evaluate its worth" (Edge, 1992, p. 68). In that way, when the speaker has identified a specific goal, he/she can continue with the trailing phase. The idea is that the understander helps the speaker to establish coherent and appropriate actions taking into account the decisions that the speaker has made previously in relation with his/her goal. Before the stages in the CDT have been concluded, the speaker is called to implement the planning phase which might include a class to be observed, a consultation with an expert, or a reading about the relevant issues identified by the speaker. Finally, participants must arrange a final meeting to share the discoveries in those chosen events.

\section{Methodology}

This study is designed under the methodology of qualitative case study, which according to Baxter and Jack (2008):

Is an approach to research that facilitates exploration of a phenomenon within its context using a variety of data sources. This ensures that the issue is not explored through one lens, but rather a variety of lenses which allows for multiple facets of the phenomenon to be revealed and understood. (p. 544)

According to Yin (2003), a case study design should be considered when: (a) you cannot manipulate the behavior of those involved in the study; (b) you want to cover contextual conditions because you believe they are relevant to the phenomenon under study; or (c) the boundaries are not clear between the phenomenon and context. In our project, the information collected was essentially understood from the speaker's perspective rather than from the understander's viewpoint which 
helped us keep the spirit of the CDT alive. As a result, the outcomes of this research are presented by describing what the participants found and gained out of this experience.

In regards to the data analysis procedure, we followed grounded theory due to its constant comparative analysis (Glaser E Strauss, 1967). In other words, the data being collected follows a constant interactive process which implies "the systematic choice and study of several comparison groups" (Glaser E Strauss, 1967, p. 9). For this reason, data are not collected all at once as a requirement to start de analysis process. On the contrary, the first data gathered may serve the researchers to reorient their research. At the same time during the data analysis, an incident should be compared and contrasted with other incidents (Corbin \& Strauss, 1990), something that supports the exchange of information that was done in each personal professional experience shared by us in this study.

Additionally, the natural essence of the 'aha' moments in this project (see the findings section below) is to produce constant information which can be also recycled at the end of each phase in order to make the necessary adjustments before the new phase starts. This idea is conceived in the grounded theory approach when Corbin and Strauss (1990) state the first principle, "since phenomena are not conceived of as static but as continually changing in response to evolving conditions, an important component of the method is to build change, through process, into the method" (p.5).

In this way, the participants and researchers spent about four months in the sessions described above using the grounded theory approach for data analysis. Throughout this time, we had two or three sessions per week which lasted two hours on average though there was no limit of time for each of them. The first session for each of the teachers playing the speaker's role was for them to tell the CI taking into account the already stated criteria proposed by Tripp (1993). We recorded each of the sessions and the understander was simultaneously and permanently taking notes of what the speaker was saying during each session, then we agreed to meet again two or three days later. In the time between the sessions, each of us was listening to the recording of the previous session. The speaker did so in order to listen to her/himself and gather her/his thoughts as a way to raise more awareness about her/his teaching practice, whereas the understander was listening to the audio in order to meet the needs of each phase of the process and to find the way to sound respectful, honest, and empathic with the questions and comments to make to the colleague in the coming session. The way we collected data was through some useful and rewarding tools like audio and video recording, and note-taking. At the planning phase, we wanted to see what changes the counterpart had decided to implement and find out how effective they were. We video recorded a class to analyze the impact that this reflection on praxis had had on the teacher's way of viewing and teaching the classes. At the same time the video was being recorded, the other teacher was informally conversing with the students about the teacher, the classes, and about whether they had noticed any changes recently in the teacher's behavior towards the class, the students, and the discipline.

In relation to the data analysis, we have said that the understander used the notes taken during the session for the speaker to mirror her/his thoughts, beliefs, attitudes, etc. displayed in the classroom, and the recordings to find out what elements were consistently appearing or were revelatory for the understander. At the same time, the speaker was using the recordings to listen respectfully and honestly to her/himself and see if she/he had clearly expressed what she/he really wanted to say or, on the contrary, if she/he really meant what she/he had said. Whatever the case, the speaker also had the chance to elaborate more on what had been partly said in the prior session or to restate what had been wrongly expressed.

After every session, we had to spend hours listening carefully to the audio, pausing it, taking notes, making connections to find possible issues that we, in any of the roles, would not have noticed during the session. We had to forward and rewind too, but this work was more exhaustive when too much time had passed between the session and the listening of the audio. In such a case, we had to listen first to the entire audio before we could 
start analyzing the data. In regard to this part of the process, we can say that it led us, as speakers, to better comprehend our teaching practices and be more reflective about each decision made, and, as understanders, to recognize that through a sense of collaborative commitment the learning opportunities about our teaching practices skyrocket.

\section{Findings}

In regards to the $\mathrm{CI}$, we may say that we were facing difficulties in the classroom unnecessarily because when we first used this tool, we immediately found how useful this instrument was to know what the source of tension in the classroom was or how the students felt about and what they thought of the class in an easy and efficient way. It was a relief to give the students the opportunity to speak their own minds, through the $\mathrm{Cl}$ instrument, and explore our own classrooms from their words because, imperceptibly, we had not noticed that when we were overwhelmed by the curriculum, the grades, the parents, the school and other things like that, we started to lose self-control or the perspective over the classroom changed negatively. This excellent exercise not only gave the students a voice but also informed us about what was missing in our teaching practices, what expectations, interests, and needs from the students needed to be satisfied and most importantly how to overcome those minimal situations. With regards to the implementation of the CDT, we are able to say that at the beginning we were a bit unsure of telling each other about the classroom problems that we were having because we did not want to be criticized, judged, sneered, or made fun of by the other colleagues. In sum, our lack of confidence was preventing us from finding a partner who we could informally and honestly talk about whatever was going wrong in the classroom. During the implementation of the CDT, we realized that this theory was not as demanding and boring as we had initially thought. On the contrary, after listening to the audio recordings, the most exciting task was to find the way of telling the counterpart about what we had found out in the recording of her/his teaching practice without intervening or imposing our personal views but guiding the other participant to see the problem through her/his own eyes just by asking the correct questions.

In general terms, we mostly gained in selfdevelopment. Nowadays, we anticipate problems and figure out possible solutions during the planning phase because we have also learned about the importance of knowing the students better and of being more aware of them during the planning. We are more oriented, as individuals and as professionals, to deal with situations in a personal learning perspective. We are also more conscious of the enormous impact our beliefs and values had on the decisions we made as teachers. Therefore, each of us has also revisited, changed, and developed those beliefs and values that were having a negative influence on our classes.

In the lines above, the authors have just explored the multiple and diverse actions that the understander and the speaker had to go through in order to guarantee the success of the CDT and the CI. The reader will better understand those roles when the participants of this project recount their experience as speakers in the reflections below. These reflections are divided into two sections called the 'aha' moment where each author highlights how relevant the role of the understander was when guiding the speaker towards new reflections and meaningful outcomes about his/her teaching practices.

\section{Teacher A's Reflection: A Professional Development Through 'aha' Moments}

Throughout my fewyears of teaching experience, several ideologies and beliefs have been ingrained in my labor as teacher, which have come out in a model that aims directly to the self of the student, more than to content. Certainly, this has not been an easy task. Teachers are always facing the barriers of an educational system that is always looking for results, which to some extent, can handicap the noble purpose of teachers of meeting their students' emotional needs.

My critical incident emerged exactly in that struggle between the results and the self. After kids finished presenting their sixth "martes de prueba" 
test-designed to assess the primary and elementary graders' competence in different subjects-I wanted to show the results they had gotten up to that point. That day I displayed the general chart to see everybody's outcomes. Kids were enthusiastic to find their names in a good rank, but obviously, there was someone in last place. This student immediately started to cry. If things could not get any worse, one student told the others about the girl's misfortune of having that "dishonored" position. When I saw that situation I felt terrible, I could not believe I had innocently exposed someone in such a discouraging way; that was not part of the beliefs that comprised my teaching model. I did not want her to feel like that only by giving priority to the results of a test. That issue and some other similar ones became part of the critical incident that I wanted to solve through the implementation of the CDT.

During the CDT process and with the aid of the understander, Teacher B, I was able to notice that some other critical incidents were missing. Initially, I thought that my problem was related to the lack of listening and attention I was giving to kids. In fact, that was just a small piece of the big puzzle that I did not know by the moment yet, something that could be evident throughout TB's attentive listening and high sense of reflection. His questions were always precise, effective, and introspective, although sometimes I could not understand how he considered some questions as relevant, if I did not. Surprisingly, they always had a logic reason. An example of this is when TB asked me: "¿Qué tan cómoda te sientes haciendo el lesson plan? How comfortable do you feel when planning a lesson? ¿Qué es lo que has encontrado más útil para tus clases? What have you found most useful for your classes?" (personal communication, June 9, 2015). At the beginning, I just wondered about the causes that made TB state those questions. But as long as I reflected on my answers, I noticed that they were leading me to a more disturbing incident, one that I had ignored completely, classroom management. Actually, there was something inside me telling me that there might be a connection between it and the CI that I presented at the beginning. Therefore, I proceeded to confirm it by contrasting some of the troublesome situations that I have had in several classes with the ones that were currently happening, and in fact, some classroom management patterns emerged from there.

Consecutively, the following movements of the male teacher were going to make me see with more clarity the failures that I had with classroom management. I checked the lesson plan format that he uses for his classes, and then he asked me to highlight the elements that I thought would help me to have more success in the lessons. "Anticipated problems" was what I chose. Thus, he told me how important that is for what he plans because it helps him to be ready for those unexpected events that could affect the development of the class. Those could go from having problems with electronic devices, carrying out activities that underestimate or overestimate the capacities of the students, to using the inappropriate materials to guide students towards the expected comprehension. One more time, TB performed the role of understander as was expected. He just gave this example of his own practice to lead me to think deeply about my own reality and to come to my own conclusions. My lessons seemed disorganized, I did not have an accurate management of time, I did not give clear instructions, nor did I have effective strategies to keep kids' attention. Definitely, classroom management was the problem in which my critical incident had to be focused on.

Evidently, despite the fact that I had my selfimprovement desire, I would not have been able to advance further without the assistance of the understander who never imposed his personal opinions or judged my reasons for classroom decisions. Conversely, he always led me to make connections with every detail I told him and was ready to unsettle me with powerful reflective questions. After each meeting, the feelings of frustration and sadness about the outcomes of my classes were fading faster than expected and were being replaced by innovative, funny, and creative teaching acts that I wanted to implement immediately with my kids.

In my opinion, each encounter was not only an opportunity to mature my vision as a teacher, but also my own humanity, full of values and beliefs. In a word, carrying the role of speaker cultivated in me the desires to review myself, to stop for a while, and to realize how my own teaching model is being built. 


\section{Teacher B's Reflection: The 'aha' Moments of an Experienced Teacher}

Being a teacher with over twenty years of experience, who lectures at the tertiary level and who has some classroom problems is an uncommon case but not rare. What makes me different from other professors who have experienced the same situation is the type of subsequent inconveniences that I have had to face in the aftermath of a fairly poor evaluation. However, nothing is as bad as it seems to be though, being honest, I did not realize that I was having classroom problems until late in 2013, when I was called by the administrative part of the university to talk about how low I had been marked by the students regarding my performance in the second semester of 2013. Although I spent all of my 2013 Christmas holiday trying to find out what could have caused this to happen and how to deal with it, that effort was fruitless as some of the problems kept arising in the first half of 2014. My struggle to find out how to develop my teaching practice continued until I learned about Farrell's critical incident as well as Edge's (1992) cooperative development theory in my master's studies. It was only at that moment when I started to be better informed about how to take more effective actions and changes in my classes.

Briefly explained, I firstly used the $\mathrm{CI}$ on my own to immediately fix what was making my class unsuccessful and the CDT, much later on with a colleague, to deal with the other necessary changes and amendments that, in the long run, would make me enhance my teaching. In the lines below, I elaborate more on how this implementation took place emphasizing the role of the understander.

When the female teacher and I decided to carefully study what was going wrong in our educational contexts, we pondered to include the invaluable contribution of the $\mathrm{CI}$ into this exercise in combination with the CDT. Thanks to this decision, other failures associated with my insufficient teaching skills emerged that until then had remained unknown and unsolved. When it came time to put all those pieces together, I realized that there were so many variables to be considered that I needed a mind map. The idea of the mind map was meaningful and useful for the purpose of analyzing, reflecting, and deciding what to do with some class disruptions and how to act more professionally on my own. However, the role my colleague played as the understander during the implementation of the CDT was much more significant. A case in point is an excerpt from the second audio. In one segment Sayra asked me:

\begin{abstract}
¿Cómo crees tú que debe ser un profesor moderno?, ¿Qué habilidades debe tener un profesor moderno? What do you think a contemporary teacher should be like? What skills should a contemporary teacher have? What I exactly answered was: "a mí me parece que un profesor debe tener la habilidad de escucha, (. . .) la habilidad de reconocer que no tiene que vivir casado con sus premisas o fundamentos; es decir que puede haber una evolución, un cambio, no sé, lo que se necesite, (. . .) la habilidad de adaptación pero no de mutación pues no creo que todos los cambios que se están dando en esta sociedad en los tiempos modernos sean para bien. I feel like a teacher should possess the ability to listen... the ability to recognize that he or she does not have to be tied to their old premises. That is, that they can change, I don't know, whatever may be necessary. The ability to adapt, but not to mutate into someone else as I don't believe that all the changes occurring in modern society are for good. (personal communication, July, 28 2015)
\end{abstract}

I still wonder how TA was able to focus on those two key words in the middle of all the thoughts and feelings shared in my previous answer. They not only triggered some additional reflections about my past and present teaching beliefs, but also they compelled me to elaborate more on myself and on how I perceived my students, their context, beliefs, interests, and needs.

The answer to the first question was confronted with another question in the same audio. In another segment TA inquired:

De lo que tú me cuentas veo mucha mentalidad flexible, abierta, es lo que suena y así fue como tú lo demostraste en la clase que te observé (. . .) entonces ahí me surge una pregunta, ¿por qué 
crees entonces que los estudiantes llegan en algún momento a aburrirse de tus clases? From what I hear, I say that you are open-minded and flexible. That is what I perceive and what I saw you demonstrate in the class I observed. From that arises a question: Why do you think students may get bored in your classes? (personal communication, July 28, 2015).

I connected this question to a previous one in which she made me think about my rapport with my students. That was the 'aha' moment of the first phase because it made me reflect on the fact that I was largely avoiding the point of being the cause of disruption in my classes; the point here is how that could be possible? For any onlooker, there is no apparent connection between the questions, and even less, a motive to activate thinking, but the truth is that with these simple questions I realized how much I boast about the things I indeed do but I tend to exaggerate, too. This was a revealing and liberating experience because if it was true that I was doing what I said, though in an exaggerated way, it was truer that I was doing not even half of the things I was in need to do. An instance of my wrong doing was the exaggerated importance I was giving to disruptive students. Another example for what I was not doing in class is that although my instructions were short they were not clear enough. This lack of clarity was the onset of confusion among students or, what was worse, the wrong perception of a teacher who improvised and changed his mind constantly when adding information to the poor instruction he had given initially. Concerning the different cultural backgrounds existing between the teacher and the students, I was not attending the values, viewpoints, styles, purposes, and objectives in life of the Tolimense students. Besides, students tended to feel affronted from the direct way I expressed my opinions and offended with how differently I treated the transgressors. Finally, the hyperbolic way of referring to my good practices made me overlook other things that my classes were missing.

The final remark I have to make concerning TA's assistance relates to two questions she asked me at two different moments during the second session. In one of those queries she asked, "¿cómo es la interacción tuya con ellos (los estudiantes)?”
[How do you interact with your students?]. In the other question she asked, "Cuéntame, ctú cómo empiezas un curso?" [Tell me, how do you begin a course?] (personal communication, August 4, 2015). Here comes a second 'aha' moment because when I blended both questions above, I realized that I was not connecting with my students individually. In other words, these questions helped me see that I was not making a conscious effort to stop and have a quick chat with the students inside or outside the classroom about whatever which, eventually, could create a comfortable environment where the students could talk to a person rather than to their teacher, an environment where they could converse about their anxieties, about anything that was going on in the classroom as well as what was holding them back.

The relevance of TA's role as understander is invaluable. She was persistent in moving back and forth to the questions that gave her hints about my relationship with my students. Additionally, through her questionnaire TA never intended to tell me what to do or how to do things, even less to judge me or criticize me. On the contrary, her questions confronted me against my own beliefs, values, opinions, interests, facts and evidences so I was able to develop and to much better clarify any contradictory view of myself and discover how to take further actions.

\section{Conclusions}

This study was developed under the frame of the $\mathrm{CI}$ and the CDT with the attempt of improving professionally the teaching practices of two English teachers. After mixing the $\mathrm{CI}$ and the CDT, other pedagogical and humanistic findings emerged to enhance the wonderful labor of the teachers. We came to conclude that $\mathrm{CI}$ helps teachers think critically of their teaching in the light of finding the everyday elements that cause class disruptions. At the same time, it makes teachers recognize what to do in order to fix classrooms situations that are going wrong.

If it is true that teachers can work together to solve problems, it is truer that sharing with colleagues our own out-of-control classroom situations is not an easy task. For that reason, the use of CDT is advisable 
to approach classroom problems because the values pertaining to CDT encourage the understander to exclude any judgmental or offensive action towards his/her peers and makes that the speakers feel comfortable and safe at talking about their $\mathrm{CI}$.

Furthermore, in an effective $C D$ team, the participants learn, inspire, and challenge each other. The individual's teaching struggles can be efficiently overcome thanks to the non-threatening environment provided by the understander who in turn promotes the speaker's self-development.

Additionally, thanks to the understander's questions and the answers with which the speaker eventually comes up with, the CDT provided us with chances to understand what we thought we did and what we actually did as much as how and why we were doing things the way we were doing them.

In sum, our professional lives have turned 180 degrees. We say so because thanks to the hybrid technique we used in this study, we were able to question the nature of our actions in the classroom, as much as we ignited a constant and permanent understanding of our teaching practice. The CDT and the $\mathrm{CI}$ together meant a deeper process of reflection about our decisions in the classroom, in the sense that it helped us uncover everyday elements that caused class disruptions with their own way of being solved. Each of the two main elements of this study largely contributed to enrich and expand our professional perspectives. In other words, having been a participant in this study symbolized a change in our teaching habits. Each meeting was always crowded of questions that made us reflect deeply in us first as a person and then as a professional, what guided us to make meaningful discoveries that eventually helped us improve our daily practices as we expected, and to open our mind to new teaching possibilities. The whole dynamic proposed by CDT led us to understand that values like respect, empathy, and honesty should be a must for teachers who want to grow professionally. In few words, +++ the incidents became catalysts for revelatory and innovative discoveries. Finally, this study proved that reflection persuaded by a peer in a safe environment promotes learning from mistakes. It also fosters permanent and meaningful changes in the teaching practice since we all have the necessary knowledge and experience to cope with any incident before it becomes unmanageable. The only thing we all need is a good partner who triggers that knowledge and experience in a persuasive way.

\section{References}

Baxter, P., \& Jack, S. (2008). Qualitative case study methodology: Study design and implementation for novice researchers. The Qualitative Report, 13(4), 544-559.

Corbin, J., \& Strauss, A. (1990). Grounded theory research: Procedures, canons, and evaluative criteria. Qualitative Sociology, 13(t), 418-427.

Edge, J. (1992). Cooperative development. ELT Journal, $46(1), 62-70$.

Farrell, T. S. C. (2008). Critical incidents in ELT initial teacher training. ELT Journal, 62(1), 3-10. doi: 10.1093/elt/ccm072

Glaser, B., E Strauss, A. (1967). The discovery of grounded theory: Strategies for qualitative research. London, UK: Weidenfeld \& Nicholson.

Johnson, K. E., \& Golombek, P. (2002). Teachers' narrative inquiry as professional development. New York, NY: Cambridge University Press.

Richards, J. C., \& T. S. C. Farrell. (2005). Professional development for language teachers. New York, NY: Cambridge University Press.

Tripp, D. (1993). Critical incidents in teaching: Developing professional judgement. London: Routledge.

Yin, R. K. (2003). Case study research: Design and methods. Thousand Oaks, CA: Sage, 3RD Edition. 